RESEARCH REPORT

\title{
Organisational downsizing and increased use of psychotropic drugs among employees who remain in employment
}

\author{
Mika Kivimäki, Teija Honkonen, Kristian Wahlbeck, Marko Elovainio, Jaana Pentti, Timo Klaukka, \\ Marianna Virtanen, Jussi Vahtera
}

J Epidemiol Community Health 2007;61:154-158. doi: 10.1136/jech.2006.050955

See end of article for authors' affiliations

Correspondence to

Professor M Kivimäki,

Department of Epidemiology

and Public Health, University

College London, 1-19

Torrington Place, London

WCIE 6BT, UK

mika.kivimaki@HI.fi

Accepted 14 June 2006

Objective: Organisational downsizing is common in modern work life, but its effect on employees' mental health is not known. The authors examined whether working in downsizing organisations predicts use of psychotropic drugs among employees who remain in employment.

Design, setting and participants: Prospective cohort study of municipal employees in Finland. 4783 employees worked in downsized units but kept their jobs after downsizing in 1993, 4271 employees lost their jobs during the downsizing, and 17599 employees did not experience downsizing. The outcome was psychotropic drug prescriptions (antidepressants, anxiolytics and hypnotics) during 1994-2000 extracted from nationwide registers and linked to the data by means of each participant's personal identification number.

Main results: After adjustment for predownsizing characteristics, employees who were exposed to downsizing but kept their jobs were at a higher risk of being prescribed psychotropic drugs (rate ratio $1.49,95 \% \mathrm{Cl} 1.10$ to 2.02 in men and $1.12,95 \% \mathrm{Cl} 1.00$ to 1.27 in women) than those not exposed to downsizing. The association of downsizing was strongest with hypnotics among the men and with anxiolytics among the women. An increased rate of psychotropic prescriptions after downsizing was also seen in male workers who lost their job (rate ratio $1.64,95 \% \mathrm{Cl} 1.19$ to 2.25 ).

Conclusions: The association between organisational downsizing and increased use of psychotropic drugs suggests that this managerial strategy may pose mental health risks among employees.

C mon trends in modern work life include global competition and organisational changes such as downinfluence the well-being of employees. ${ }^{1}$ Yet work life has received little attention in research on the aetiology of psychiatric disorders. ${ }^{23}$

Several observational studies suggest that perceived stressful work conditions, such as high work demands, lack of control at work and problems in interpersonal relations, are associated with poor mental health and self-reported use of psychotropic drugs. ${ }^{4-10}$ However, the nature of these associations is unclear because the evidence relies on self-assessments of work-related stressors. Instead of organisational realities, a negative perception of work may reflect subclinical or undiagnosed mental disorders. Most studies have also assessed mental health and prescriptions via self-assessments, and thus these data are additionally open to bias due to common-method variance.

Organisational downsizing has been found to elicit considerable stress due to heightened workload, increased job insecurity and reduced job control for those who remain in employment. ${ }^{11}$ Employees working in downsized workplaces have also been found to be at increased risk of stress-related physical health problems, as indicated by higher levels of post-downsizing sickness absence and trauma, self-reported morbidity, early retirement and cardiovascular mortality. ${ }^{11-19}$ In studies of downsizing as a work stressor, a methodologically desirable measure is the possibility to use objective assessments through the determination of actual changes in staffing levels. Thus problems related to reporting bias and common-method variance are avoided.

In this study, we explored the association between organisational downsizing and subsequent psychiatric disorders, as indicated by psychotropic drug prescriptions. We hypothesised that downsizing predicts increased risk for psychotropic drug use.

\section{MATERIALS AND METHODS \\ Participants}

This study is part of the ongoing 10-Town study examining work-related determinants of health in the entire staff of fulltime municipal employees working in 10 Finnish cities. ${ }^{18}$ We included the four cities (Espoo, Turku, Vantaa, Raisio) in which the employers' computer-stored records of staffing levels covered the period from 1991 to 2000 . The total number of personnel in these cities fell by $11.3 \%$ between 1991 and 1993 , but only by $1.3 \%$ between 1993 and 1994. Thereafter, the figures started to increase slightly.

The eligible population was 26682 employees aged 1962 years who were in the service of the four cities in 1991 (fig 1). Of them, 22382 (5893 men and 16489 women) remained in employment during the years of downsizing (1991-3), 4783 (932 men and 3851 women) working in groups that were considerably downsized. In contrast, 4271 employees (727 men, 3544 women) lost or left their jobs during the downsizing between 1991 and 1993 (for example, due to redundancy, voluntary turnover or retirement).

Information on drug prescriptions was extracted from the national register kept by the Social Insurance Institution of Finland and linked to the data by means of each participant's personal identification number (a unique number that all Finns receive at birth and that is used for all contacts with the social welfare and healthcare systems). The register data covered the period from 1994 to the end of 2000 or the year the participant died $(\mathrm{n}=327)$, if earlier (mean follow-up 6.9 years). 


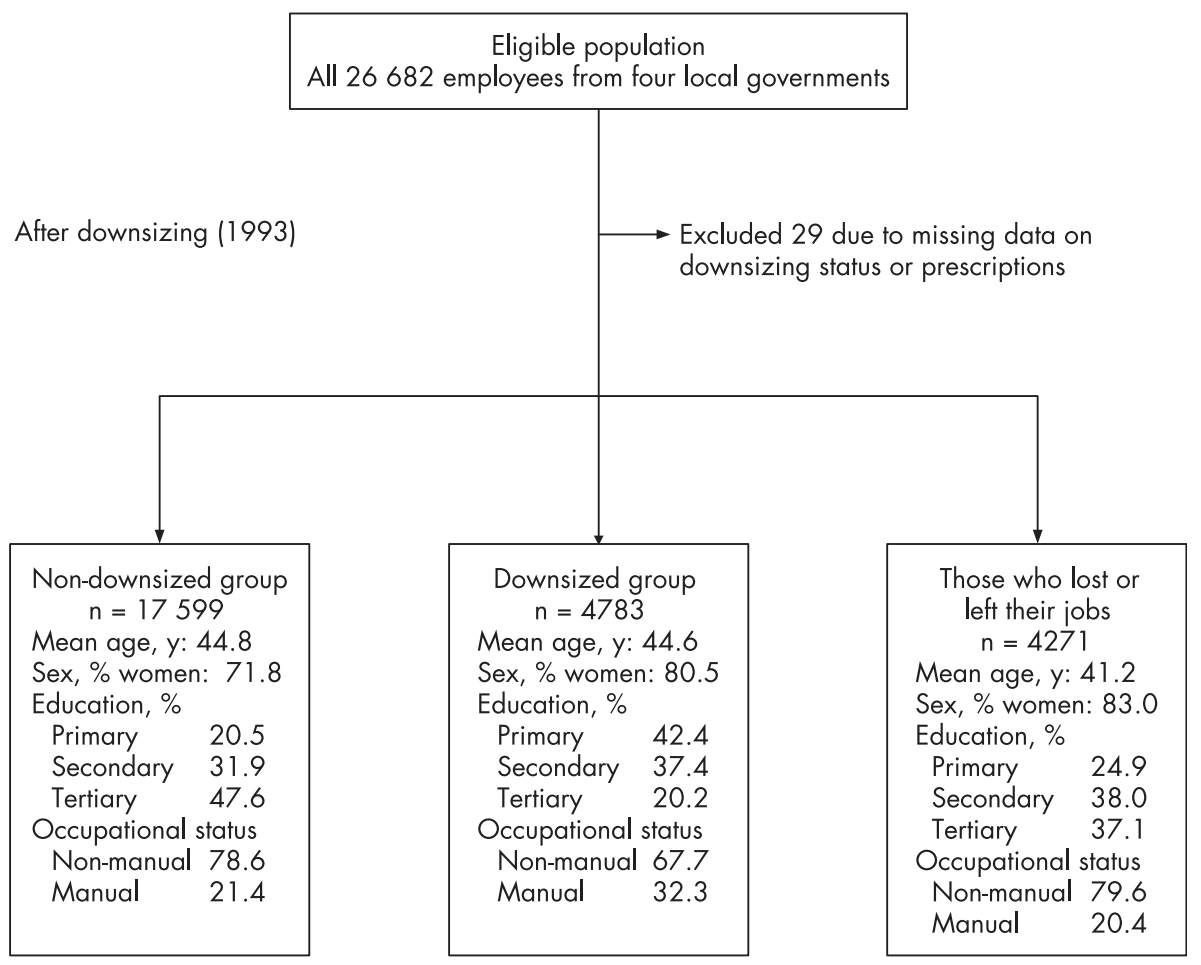

\section{Assessment of downsizing}

The data on downsizing were obtained from the employers' records covering all periods of full-time employment, including the date of commencement and, where appropriate, the termination of work contracts, and Statistic Finland occupational title. ${ }^{20}$ Personnel reduction in a group of employees was defined as previously. ${ }^{11} 1215-19$

$$
\begin{aligned}
& \left(\frac{\text { (Total number of person-years before downsizing) }}{\text { (Total number of person-years before downsizing) }}\right. \\
& \left.-\frac{\text { (Total number of person-years after downsizing) }}{\text { (Total number of person-years before downsizing) }}\right) \times 100
\end{aligned}
$$

We calculated the personnel reduction for all of the occupational groups in each city by comparing the total number of person-years worked in the group in 1993 with the corresponding person-years in 1991. Thus, the percentage of personnel reduction was obtained for 272 employee groups and this percentage was linked to all of the members of each group to obtain a measure of downsizing. In keeping with previous analyses we defined a downsizing organisation as one that reduced its workforce by $18 \%$ or more. ${ }^{11}{ }^{12} 15-19$

\section{Assessment of drug prescriptions}

Data on psychotropic drug prescriptions were collected from the National Prescription Register, managed by the Social Insurance Institution of Finland. ${ }^{21}$ The national sickness insurance scheme covers the entire population, regardless of age or occupational status, and provides reimbursement for virtually all filled prescriptions. The prescription register of the Social Insurance Institution is comprised of outpatient prescription data based on the World Health Organization Anatomical Therapeutic Chemical (ATC) classification code. ${ }^{22}$
In Finland, all prescriptions are written by a physician and each prescription can cover antidepressant use for a maximum of three months. The Social Insurance Institution obtains these data from all pharmacies in Finland as part of the national drug reimbursement scheme. ${ }^{23}$

The number of prescriptions for psychotropic drugs, such as antidepressants (ATC code N06A), anxiolytics (NO5B) and hypnotics (NO5C), and for all other prescriptions were calculated for each participant between 1 January 1994 and 31 December 2000. There were no registered data on predownsizing prescriptions available, because the National Prescription Register for these data was not set up until 1994.

\section{Assessment of pre-downsizing characteristics}

The workers' sex, age and occupational status before downsizing (manual $v$ non-manual) were derived from the employers' records in 1991. Education (primary, secondary or tertiary) was obtained from the Statistics Finland registers.

\section{Statistical analyses}

Analyses were performed separately for men and women, because psychotropic drug use and determinants of mental health vary between sexes. ${ }^{5624}$ Employees were categorised into three groups: (1) employees in downsized group: if the reductions in personnel were greater than $18 \%$; (2) employees who lost or left their jobs during downsizing; and (3) employees in non-downsized group (the reference group).

We analysed between-group differences in the pre-downsizing characteristics with $\chi^{2}$ test for sex and employer and with analysis of variance for age. The frequency of prescriptions demonstrates a skewed distribution-low values being the most frequent and high values being rarely observed (that is, a negative binomial distribution). Thus a negative binomial regression analysis was performed to assess associations between post-downsizing status and the rates of psychotropic and other drug prescriptions. We calculated the rate ratios for 
Table 1 Proportion of employees with psychotropic drug prescriptions and other prescription over the 7-year study period and rate of drug prescriptions by sex

\begin{tabular}{|c|c|c|c|c|}
\hline & \multicolumn{2}{|c|}{ Men $(n=6620)$} & \multicolumn{2}{|c|}{ Women $(n=20033)$} \\
\hline & No of cases & $\begin{array}{l}\text { Rate per } 1000 \\
\text { person-years }\end{array}$ & No of cases & $\begin{array}{l}\text { Rate per } 1000 \\
\text { person-years }\end{array}$ \\
\hline Psychotropic prescriptions & 1526 & 51.4 & 6380 & 59.1 \\
\hline Antidepressants & 892 & 18.9 & 3582 & 25.8 \\
\hline Anxiolytics & 835 & 19.2 & 3594 & 19.3 \\
\hline Hypnotics & 762 & 13.4 & 2944 & 14.0 \\
\hline Other prescriptions & 6120 & 265.9 & 19472 & 379.5 \\
\hline
\end{tabular}

the downsized group and the group who lost or left their job during the downsizing using the non-downsized group for comparison, while controlling for the effect of the pre-downsizing characteristics by including them in the model as independent variables.

To examine whether the effects of downsizing on psychotropic prescriptions were different for non-manual and manual employees, we carried out a stratified analysis by occupational status. All the analyses were performed with the use of SAS software, version 8.2 (SAS Institute, Cary, North Carolina, USA).

\section{RESULTS}

Figure 1 presents characteristics of the participants by postdownsizing status. Participants who were employed in groups not exposed to downsizing were older, more often male and had higher educational attainment than those who worked in the downsized groups or who left or lost their jobs during the downsizing (all $\mathrm{p}<0.001)$. Occupational status in downsized groups was lower than that in other groups $(p<0.001)$.

\section{Downsizing and subsequent psychotropic drug prescriptions}

Altogether 806992 prescriptions (145 112 for men and 611880 for women) were recorded during the follow-up for the participants. As shown in table 1, women were more often prescribed psychotropic drugs, especially antidepressants, and other drugs than men (all $\mathrm{p} \leqslant 0.004$ ).

Table 2 presents the association between post-downsizing status and the subsequent rate of prescriptions. After adjustment for age and employer, the men exposed to downsizing had a $1.43(95 \%$ CI 1.07 to 1.91$)$ times greater rate of psychotropic prescriptions than the men with no downsizing (data not shown). A further adjustment for education and occupational status had little effect on this rate ratio (table 2). A similar increased rate was seen among the men who lost or left their jobs during downsizing (rate ratio 1.6). For the women, downsizing was associated with a slightly increased rate of psychotropic prescriptions.

A stratified analysis by specific psychotropic drug prescriptions showed that the associations of downsizing were strongest with hypnotics (rate ratio $1.81,95 \%$ CI 1.21 to 2.70 , $\mathrm{p}=0.004)$ among the men and with anxiolytics (1.30,95\% CI 1.12 to $1.52, \mathrm{p}<0.001$ ) among the women (data not shown). Those men who lost or left their job during downsizing had also a 1.2-fold increased rate of other prescriptions.

\section{Socioeconomic differences}

Table 3 presents the association between post-downsizing status and subsequent psychotropic drug prescriptions by occupational status. In the men, downsizing was associated with increased prescription rate in both non-manual and manual groups. In the women, this was the case only for non-manual group and the effect was substantially smaller.

\section{DISCUSSION}

This quasi-experimental outcome study of 26653 city employees suggests that downsizing is a mental health risk, not only for employees who loose their jobs, but also for those who remain in employment. Men who kept their jobs after downsizing had a significantly higher rate of psychotropic prescriptions than men who worked in non-downsized groups when controlled for pre-downsizing characteristics. For women, organisational downsizing was associated with slightly increased psychotropic prescription rate (anxiolytics in particular). The highest rate of psychotropic prescriptions after downsizing was seen in male manual workers who lost their jobs.

This study has several important methodological advantages. The putative stressor, downsizing, was uniform for all of the participants in the quasi-experimental groups, and clearly separable from the putative consequences of the stressor. Data about prescriptions came from comprehensive national registers, and information about downsizing was obtained from

Table 2 Negative binomial regression models for rate of psychotropic drug prescriptions and other prescriptions by postdownsizing status

\begin{tabular}{|c|c|c|c|c|c|}
\hline \multirow[b]{2}{*}{ Post-downsizing status } & \multirow[b]{2}{*}{ Participants (n) } & \multicolumn{2}{|l|}{ Psychotropic drug } & \multicolumn{2}{|l|}{ Other prescriptions } \\
\hline & & Rate ratio $(95 \% \mathrm{Cl})$ & p Value & Rate ratio $(95 \% \mathrm{CI})$ & p Value \\
\hline \multicolumn{6}{|l|}{ Men } \\
\hline Employed in non-downsized group & 4961 & 1.00 & & 1.00 & \\
\hline Employed in downsized group & 932 & $1.49(1.10-2.02)$ & 0.009 & $1.03(0.94-1.12)$ & 0.54 \\
\hline Lost or left their job during downsizing & 725 & $1.64(1.19-2.25)$ & 0.002 & $1.16(1.06-1.27)$ & 0.002 \\
\hline \multicolumn{6}{|l|}{ Women } \\
\hline Employed in non-downsized group & 12638 & 1.00 & & 1.00 & \\
\hline Employed in downsized group & 3851 & $1.12(1.00-1.27)$ & 0.05 & $0.99(0.95-1.02)$ & 0.50 \\
\hline Lost or left their job during downsizing & 3542 & $1.05(0.93-1.19)$ & 0.42 & $0.97(0.94-1.01)$ & 0.11 \\
\hline
\end{tabular}

Rate ratios and $95 \%$ confidence intervals $(\mathrm{Cl})$ are adjusted for age, education, occupational status and local government. 
Table 3 Negative binomial regression models for rate of psychotropic drug prescriptions by post-downsizing status and occupational status before downsizing

\begin{tabular}{|c|c|c|c|c|c|c|}
\hline \multirow[b]{2}{*}{ Post-downsizing status } & \multicolumn{3}{|l|}{ Non-manual } & \multicolumn{3}{|l|}{ Manual } \\
\hline & Participants (n) & Rate ratio $(95 \% \mathrm{Cl})$ & p Value & Participants (n) & Rate ratio $(95 \% \mathrm{Cl})$ & p Value \\
\hline \multicolumn{7}{|l|}{ Men } \\
\hline Employed in non-downsized group & 3285 & 1.00 & & 1676 & 1.00 & \\
\hline Employed in downsized group & 254 & $1.87(1.11-3.12)$ & 0.02 & 678 & $1.70(1.12-2.60)$ & 0.01 \\
\hline Lost or left their job during downsizing & 467 & $1.40(0.94-2.08)$ & 0.09 & 258 & $2.16(1.24-3.76)$ & 0.007 \\
\hline \multicolumn{7}{|l|}{ Women } \\
\hline Employed in non-downsized group & 10545 & 1.00 & & 2093 & 1.00 & \\
\hline Employed in downsized group & 2985 & $1.20(1.04-1.37)$ & 0.01 & 866 & $0.84(0.64-1.10)$ & 0.21 \\
\hline Lost or left their job during downsizing & 2929 & $1.15(1.01-1.32)$ & 0.04 & 613 & $0.71(0.53-0.94)$ & 0.01 \\
\hline
\end{tabular}

employers' files. Therefore, the study did not rely on selfreported data from employees and was not subject to common method variance bias. Previous studies of work stress and mental health have exclusively used self-reported data on workplace exposures. ${ }^{4-10}$

\section{Downsizing as a predictor of psychiatric disorders requiring treatment}

We studied downsizing during a major national recession, when the unemployment rate nearly tripled during a two-year period and reached the rather substantial rate of $17 \% .{ }^{25}$ Cities and towns were forced to downsize personnel to save costs, but the legislation did not allow parallel cuts in the services provided. In the downsized groups, the cuts resulted in greater levels of job demands and job insecurity with a concomitant decrease in job control, ${ }^{11}$ that is, changes that characterise increased work stress according to the job strain model and the effort-reward imbalance model. ${ }^{26}{ }^{27}$ Indeed, organisational downsizing has been shown to be a strong predictor of stressrelated physical health outcomes, including cardiovascular mortality. ${ }^{11-19}$

In men, downsizing was associated with increased psychotropic prescription rate among both non-manual and manual groups. In women, this was the case only for non-manual group and the effect was substantially smaller. Findings from previous studies also suggest that the effects of work stressors on mental health may vary by gender. ${ }^{56}{ }^{10}$ For example, the association between job insecurity (a correlate of downsizing) and depressive symptoms was stronger for men than women in a representative sample of the Danish workforce. ${ }^{10}$ A Swedish study showed that a combination of stressful conditions at work and at home predicted perceived symptoms in women, whereas for men symptoms were more strongly determined by work stress alone. ${ }^{28}$

These findings underline the importance of conducting analyses stratified by sex and socioeconomic position when studying the effects of downsizing on mental health. Further research is needed to determine whether the observed differences may in part be explained by different changes in work after downsizing between men and women and socioeconomic groups, or whether more general differences in the meaning of work-and thus differences in the vulnerability to work changes-might underlie these results.

\section{Limitations}

Our results should be interpreted in light of some limitations. The selection of variables included in the analysis was largely dependent on the availability of data in source registers, making some variables of interest absent in this study. A drawback was that prescription records were available only for the post-downsizing period from 1994 onwards. In order to analyse the immediate consequences of the changes at work, the follow-up time should have begun from the first experiences of downsizing. It is probable that we lost many cases in downsized groups in 1991-3 (before starting follow-up) and thus the effect of downsizing may be underestimated in our findings.

As we had no data on prescriptions at the pre-downsizing phase, it is also important to consider selective retention, an issue that may lead to an overestimation of the effect of downsizing. Selective retention (that is, employees with poor mental health remaining in downsized groups) may explain the observed associations between downsizing and an increased risk of being prescribed psychotropic drugs if those who lost their jobs had significantly less psychotropic drugs prescriptions than those who remained. Our findings on men suggest that this was not the case: those who lost their jobs during downsizing had a higher risk of being prescribed psychotropic drugs than employees with no downsizing.

For observational studies without randomisation, the possibility of confounding remains. In this study, socioeconomic position is a potential confounding factor for the observed association between downsizing and psychotropic prescriptions. However, there are two reasons why we think this is unlikely. First, controlling for the effects of education and occupational status (two major socioeconomic indicators) had little effect on this association among the men. Second, a stratified analysis showed similar effects of downsizing on psychotropic prescriptions for both non-manual and manual men. If confounded, the association between downsizing and prescriptions would differ in terms of direction or magnitude between levels of socioeconomic position.

Finally, corresponding to Finnish municipal workers in general, ${ }^{25}$ our cohort was $74 \%$ female and racially homogeneous (white employees). Future research with more diverse samples is needed to evaluate the generalisability of our findings, and additional data on the employment of those who are downsized would complement such an analysis.

\section{Conclusions}

In summary, as demonstrated in this quasi-experimental study based on register sources and other studies using self-reports, ${ }^{4-}$ ${ }_{10}$ measurements within working populations and those sensitive to minor psychiatric disorders reveal that work may include significant risk factors for mental health. There may be several reasons why stressful conditions at work have received little attention as risk factors in previous psychiatric research. In clinical populations including both the employed and the unemployed, the protective aspects of work may mask any effects of work-related risks. Moreover, survival bias may prevent effective detection of the adverse effects of work, as major psychiatric disorders are a common cause of work disability and a potential selective factor for unemployment (which further increases the risk of psychiatric disorders). 


\section{What is already known}

- Organisational downsizing is common in modern work life.

- Organisational downsizing has been found to increase workload and reduce job security and job control for those who remain in employment.

- The effect of downsizing on mental health has remained unclear.

\section{What this paper adds}

- Employees who remained in work were at increased risk of being prescribed psychotropic drugs after downsizing.

- In men, downsizing was associated with increased psychotropic prescription rate among both non-manual and manual groups.

- In women, this was the case only for non-manual groups and the effect was substantially smaller.

\section{Policy implications}

- Policy makers, employers, and occupational health professionals should recognise that organisational downsizing may pose mental health risks among employees.

- The observed excess risk of being prescribed psychotropic drugs after downsizing among employees indicates a burden, not only on the individual, but also on society.

The observed 1.1-1.9-fold excess risk of being prescribed psychotropic drugs after downsizing among the men and women indicate a great burden, not only on the individual, but also on society. Our findings imply that work conditions should increasingly be recognised in large-scale preventive strategies for psychiatric disorders.

\section{ACKNOWLEDGEMENTS}

This study was supported by the Academy of Finland (projects 117604 and 105195), the Finnish Work Environment Fund (projects 101190 and 103432), the Finnish Local Government Pensions Institution and the participating towns. We thank Professor David Gunnell for his insightful comments to an earlier version of this paper.

\section{Authors' affiliations}

T Honkonen, J Pentti, M Virtanen, J Vahtera, Finnish Institute of Occupational Health, Helsinki, Finland

M Kivimäki, Department of Epidemiology and Public Health, University College London, London, UK

K Wahlbeck, M Elovainio, National Research and Development Centre for Health and Welfare, Helsinki, Finland

T Klaukka, Social Insurance Institution, Helsinki, Finland

\section{REFERENCES}

1 Gowing MK, Kraft JD, Campbell Quick J. The new organizational reality: downsizing, restructuring, and revitalization. Washington, DC: American Psychological Association, 1998

2 Kendler KS, Gardner CO, Prescott CA. Toward a comprehensive developmental model for major depression in women. Am J Psychiatry 2002;159:1133-45.

3 Kessler RC, Berglund P, Demler O, et al. National Comorbidity Survey Replication. The epidemiology of major depressive disorder: results from the National Comorbidity Survey Replication (NCS-R), JAMA 2003;289:3095-105.

4 Appelberg K, Romanov K, Honkasalo ML, et al. The use of tranquilizers, hypnotics and analgesics among 18,592 Finnish adults: associations with recent interpersonal conflicts at work or with a spouse. J Clin Epidemiol 1993:46:1315-22.

5 Stansfeld SA, Fuhrer R, Shipley MJ, et al. Work characteristics predict psychiatric disorder: prospective results from the Whitehall II study. Occup Environ Med 1999:56:302-7.

6 Paterniti S, Niedhammer I, Lang T, et al. Psychosocial factors at work, personality traits and depressive symptoms: longitudinal results from the GAZEL Study. Br J Psychiatry 2002;181:111-17.

7 Kivimäki M, Elovainio M, Vahtera J, et al. Association between organisational inequity and incidence of psychiatric disorders in female employees. Psychol Med 2003:33:319-26.

8 Wang J. Work stress as a risk factor for major depressive episode(s). Psychol Med 2005;35:865-71.

9 Ylipaavalniemi J, Kivimäki $M$, Elovainio $M$, et al. Psychosocial work characteristics and incidence of newly diagnosed depression: a prospective cohort study of three different models. Soc Sci Med 2005;61:111-22.

10 Rugulies R, Bultmann U, Aust B, et al. Psychosocial work environment and incidence of severe depressive symptoms: prospective findings from a 5-year follow-up of the Danish Work Environment Cohort Study. Am J Epidemiol, 2006;29 [Epub ahead of print].

11 Kivimäki M, Vahtera J, Pentti J, et al. Factors underlying the effect of organisational downsizing on health of employees: a longitudinal cohort study. BMJ 2000;320:971-5.

12 Vahtera J, Kivimäki M, Pentti J. Effect of organisational downsizing on health of employees. Lancet 1997; 350:1124-8.

13 Woodward CA, Shannon HS, Cunningham C, et al. The impact of reengineering and other cost reduction strategies on the staff of a large teaching hospital. A longitudinal study. Med Care 1999;37:556-69.

14 Quinlan M, Mayhew C, Bohle P. The global expansion of precarious employment, work disorganization, and consequences for occupational health: a review of recent research. Int J Health Serv 2001;31:335-414.

15 Kivimäki M, Vahtera J, Ferrie JE, et al. Organisational downsizing and musculoskeletal problems in employees: a prospective study. Occup Environ Med 2001:58:811-17.

16 Theorell T, Oxenstierna G, Westerlund $H$, et al. Downsizing of staff is associated with lowered medically certified sick leave in female employees. Occup Environ Med 2003;60:E9.

17 Westerlund H, Ferrie J, Hagberg J, et al. Workplace expansion, long-term sickness absence, and hospital admission. Lancet 2004:363:1193-7.

18 Vahtera J, Kivimäki M, Pentti J, et al. Organisational downsizing, sickness absence and mortality: the 10-Town prospective cohort study. BMJ 2004;328:555-7.

19 Vahtera J, Kivimäki M, Forma $P$, et al. Organizational downsizing as a predictor of disability pension: the 10-Town prospective cohort study. J Epidemiol Community Health 2005;59:238-42.

20 Statistics Finland. Classification of occupations, Handbook no 14. Helsinki Statistics Finland, 1987.

21 National Agency for Medicines. Finnish Statistics on Medicines 2000. Helsinki: National Agency for Medicines and Social Insurance Institution, 2001

22 WHO Collaborating Centre for Drug Statistics Methodology. Guidelines for ATC classification and DDD assignment. Oslo: WHO collaborating centre for drug statistics, 2004.

23 Martikainen J, Rajaniemi S. Drug reimbursement system in EU member states, Iceland and Norway, Social security and health reports 54 . Helsinki, Finland: The Social Insurance Institution, 2004.

24 Paulose-Ram R, Jonas BS, Orwig D, et al. Prescription psychotropic medication use among the U.S. adult population: results from the third National Health and Nutrition Examination Survey, 1988-1994, J Clin Epidemiol 2004;57:309-17.

25 Statistics Finland. Statistical yearbook of Finland 1991-1999. Helsinki: Statistics Finland, 1999

26 Karasek R, Theorell T. Healthy work: stress, productivity, and the reconstruction of working life. New York: Basic Books, 1990.

27 Siegrist J. Adverse health effects of high-effort/low-reward conditions. J Occup Health Psychol 1996;1:27-41

28 Krantz G, Berntsson L, Lundberg U. Total workload, work stress and perceived symptoms in Swedish male and female white-collar employees. Eur J Public Health 2005;15:209-14. 